\title{
Study of interface composition and height column during absorption process
}

\author{
Beltrán-Prieto Juan Carlos ${ }^{1 *}$, Kolomazník Karel ${ }^{1}$ \\ ${ }^{1}$ Faculty of Applied Informatics, Tomas Bata University in Zlín, nám. T. G. Masaryka 5555, 76001 Zlín, Czech Republic
}

\begin{abstract}
Packed and tray columns are widely used in the study of gas-liquid interaction during mass and heat transfer process. There exist a variety of column configurations and each design is performed according to specific purposes, such as nature of processing feed, number of components, product streams, type of operation, etc. Continuous contact between phases allows mass transfer, which is the case of process like absorption, distillation and extraction were fluid phases can be added at constant rate to the column. Understanding of mass transfer during such process is important for design purposes because proper design will allow correct separation and extraction of components. The concentration of components being transferred changes as it flows through the column. As a result, the concentration driving force changes along the height of the column. In the present paper we aim to model a gas absorption process after performing a mass balance along the column and determining the interface composition (mole fraction) and height of a packed tower.
\end{abstract}

\section{Introduction}

Gas absorption is an operation of mass transfer that consists in the separation of components of a gaseous mixture by contact with a suitable fluid. Mass transfer separation operations involve the contact of two immiscible phases, sometimes is intermittent (i.e. staged columns) and other continuous, (i.e. packed columns). There exist several means to achieve the mass transfer between fluid phases (i.e. by diffusion or by convective mass transfer). There are cases for example. In which a solute diffuses through a vapor phase and later is absorbed in an immiscible fluid phase, like in the absorption of ammonia from air using water. During the process, both phases remain in contact and a concentration gradient is generated in each phase, which allows the mass transfer process. The determination of concentration profile and mass transfer rates is normally of particular interest during the analysis of this process, where equilibrium relations play an important role. For this, is important to keep in mind concepts related to equilibrium relation in fluid systems, Henry's law, and equilibrium distribution coefficients. Absorption is used in vapor recovery from gas streams, gas treatments in refineries, and also for the purpose of waste treatment from industrial sources. During this process, a fluid that exerts a differential solvent effect on the components of the gas is used. Normally, once absorption process is completed, it is desired to regenerate and recycle the absorbent and recovery of the absorbed compounds. For this purpose, a stripping process is subsequently carried out. During these two operations, mass or molar flow rates do not remain constant. When only one of the components is being transferred between phases it is convenient to differentiate the flow rate and solute free phase for purpose of modeling the total flow rate, the mass balance around the lower end of the column, graphical determination of number of theoretical trays among other calculations [1].

Understanding of gas adsorption process is important in fluid stream analysis, study of hydrodynamic features of a packed column, determination of fluids mass balance [2], calculation of parameters such as mass transfer coefficients, design of plate absorption towers, drag and flooding flows calculation, study of physicchemical properties and composition of fluids, component recovery contained in fluid streams, industrial design, process simulation, evaluation of the influence of parameters (i.e. diameter of column, packing height, mass transfer coefficient, molar flow rates, number of trays) [3], process design, countercurrent two-phase flow studies [4], determination of operation line and equilibrium line, optimum stream ratio (inert liquid and gas), effective packing surface area, influence of packing type, evaluation of column efficiency for fractionators, absorbers and strippers [5]. They have successfully been used in the removal of air pollutants, odor elimination, in the food industry during the treatment of waste and reuse in the processes, stripping of contaminants from flow stream, absorption in the solvay process where sodium bicarbonate $\left(\mathrm{NaHCO}_{3}\right)$, and this can be used in effervescent drinks such as fruit juices and baking powder, is produced; absorption in production processes of nitric acid, used as a descaling agent (products that prevent or eliminate the deposit of salts that are formed on the walls) as well in

\footnotetext{
Corresponding author: prieto@fai.utb.cz
} 
the agriculture and food industry and recovery of organic compounds from aqueous streams. Additionally, it has been used in absorption and desorption of $\mathrm{CO}_{2}$ [6], control of $\mathrm{CO}_{2}$ emissions [7]. It has been reported that the increment in removal efficiency is proportional to the liquid flow rate and solvent concentration. Additionally, gas mass transfer rate increases with an increase in the liquid flow rate [8]. Comparative studies between membrane contactors and absorption towers for post combustion $\mathrm{CO}_{2}$ capture [9]. Accordingly, simulations have been performed using an absorber model with the corresponding experimental validation in a membrane contactor setup. Using membrane absorbers often require gas treatment. Membranes acts as non-selective barrier between the gas and the solvent and requires the pore size to be larger than the mean free path of diffusing gas. Selection of membrane material depends on chemical solvent properties. In the present paper, we analyze a gas stream that contains a defined amount of a gas, which is reduced after passing through a packed absorption tower.

In order to improve the contact between the liquid and the vapor and make more efficient the transport process during absorption or distillation stages, plate towers are generally used. The contact between these phases is achieved either in countercurrent flow or with cross flow of liquid against vapor flow upward. There exist several configurations depending on the type of flow. In the case of countercurrent flow, the main configurations are dualflow with round holes, turbogrid and ripple trays. However, there are some disadvantages associated to this type of configuration like low turndown ratio (the liquid drains completely off the tray at lower vapor rates) and so, these arrays have not been commonly used. On crossflow set up, the main configurations are sieve tray, valve tray, and bubble cap tray. The spacing of each tray is determined after consideration of vapor velocity, vessel diameter and accessibility of trays to maintenance. In sieve tray, for example, there are holes of diameter equal to $3-12 \mathrm{~mm}$ through which gas bubbles pass through the flowing fluid, which is prevented from flowing down through the holes due to the kinetic energy of the gas. In this system, the level of the fluid is maintained with an overflow weir while the gas ascends through the holes at enough rate to keep most of the liquid from weeping through. Around $5-15 \%$ of the total area corresponds to active cross section. These measurements depend on pressure drop values, mass transfer efficiency, weeping and entrainment. Some factors such as vapor rate, density, weir length and tray spacing are important for the determination and calculation of tower diameter. When valve openings are used, there exist liftable caps that cover the valve trays and through which the vapor flows horizontally into the liquid, providing better mixing in comparison to sieve trays. Additionally, in most cases, the cost associated to the design and construction of valve trays is usually less than sieve trays due to the larger holes and thicker plates which need less support [1]. When tray equipment is used, there occurs a stepwise change in concentration, on the other hand, when packed towers are used, the variation in concentration occurs gradually. Previously, packed towers were generally used in small equipment, for low pressure drop and in cases when it was necessary the consideration of corrosive conditions, however this has changed and currently both type of equipment are competitive and generally used for different purposes and scales. When it is desired to disperse the gas on the tray and maintain a minimum liquid level, bubblecap trays is used. However, they are normally associated with considerable costs, hydraulic gradient problems and therefore are not commonly installed. Their most common use is the low liquid flow rate situations as in crude vacuum towers. Other problems associated to this type of array are the variation in vapor flow across the cross section and efficiency degradation. The design of absorption columns requires determination of column height, column diameter to handle liquid and gas flow rates and proper selection of column internal features (packing support, fluid distributor) [10]. When equilibrium data is available, it is possible to determine the number of equilibrium stages for a particular fluids separation process. However, this is not always possible in trays and the theoretical stage is a highly variable quantity. In the case of tower with diameters higher than $3 \mathrm{~m}$, concentration gradients along the path of liquid flow are formed and the amount of mass transfer is higher than the calculated considering the average terminal compositions. Flow rates, viscosities, relative volatilities, surface tension, geometrical configuration of the tray or packing and other parameters associated to Reynolds and Schmidt dimensional numbers affect the efficiency of trays and packings.

It is difficult to perform an experimental measurement of interfacial area between the liquid and the gas. Moreover, it is also complicated the determination of film and overall coefficients $k_{x}^{\prime}, k_{y}^{\prime}, K_{x}^{\prime}$ and $K_{y}^{\prime}$. Generally, the measurements performed yield a volumetric mass-transfer coefficient which contains the interfacial area and mass transfer coefficient.

Experimental measurements in a packed tower yield a volumetric mass transfer coefficient that combines the interfacial area and mass transfer coefficient [11]. We aim to study this type of system and determine the tower height using $k_{y}^{\prime} a$.

\section{Description of the system}

For the present system, we take into consideration numerical values of $k_{y}^{\prime} a=0.0739 \mathrm{~kg} \mathrm{~mol} / \mathrm{s} \cdot \mathrm{m}^{3}$. molfrac and $k_{x}^{\prime} a=0.169 \mathrm{~kg} \mathrm{~mol} / \mathrm{s} \cdot \mathrm{m}^{3} \cdot \mathrm{molfrac}$, also we consider that the process occurs at $293 \mathrm{~K}$ and $1.013 \times 10^{5} \mathrm{~Pa}$. The overall mass balance applied on a solute in a packed absorption tower which is diffusing through a stagnant gas and then into a stagnant fluid can be expressed as :

$$
L^{\prime}\left(\frac{x_{2}}{1-x_{2}}\right)+V^{\prime}\left(\frac{y_{1}}{1-y_{1}}\right)=L^{\prime}\left(\frac{x_{1}}{1-x_{1}}\right)+V^{\prime}\left(\frac{y_{2}}{1-y_{2}}\right)
$$

were $y_{1}$ and $x_{1}$ are the mol fraction of solute in the gas and liquid respectively [12]. 


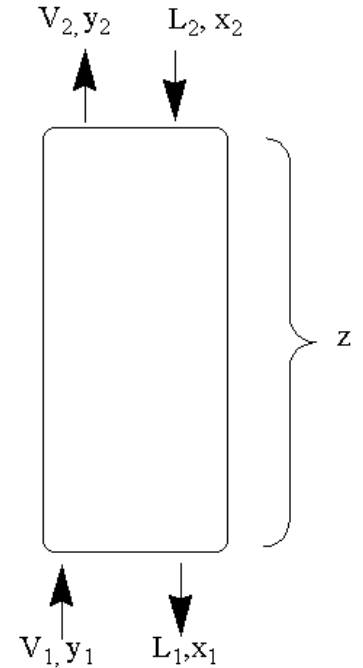

Fig. 1. General description of the system under study. Mass balance in absorption column.

For numerical analysis, we consider the case of a 1 mol\% gas entering the column $\left(y_{1}=0.01\right)$ and 0.05 mol $\%$ as outlet. $\left(y_{2}=0.0005\right)$. Additionally, we take into account an inert liquid flow $\left(L^{\prime}\right)$ of $100 \mathrm{~kg} \mathrm{~mol} / \mathrm{h}$, while the inert gas flow $\left(V_{1}\right)$ is $90 \mathrm{~kg} \mathrm{~mol} / \mathrm{h}$. We then proceed with following calculations:

$V^{\prime}=(90 \cdot[1-0.01])=89.1 \mathrm{~kg} \mathrm{~mol}$ inert air $/ h$, $V_{2}=V^{\prime} /(1-0.0005)=\left(89.1 \mathrm{~kg}\right.$ mol inert $\left.\frac{\text { air }}{h}\right) /(1-$ $0.0005)=89.1446$. Additionally,

$$
100\left(\frac{0}{1-0}\right)+89.1\left(\frac{0.01}{1-0.01}\right)=100\left(\frac{x_{1}}{1-x_{1}}\right)+89.1\left(\frac{5 \times 10^{-4}}{1-5 \times 10^{-4}}\right)
$$

Which leads to $x_{1}=0.008478$. We now proceed to perform a mass balance to calculate an intermediate point in the operation line,

$$
L^{\prime}\left(\frac{x}{1-x}\right)+V^{\prime}\left(\frac{y_{1}}{1-y_{1}}\right)=L^{\prime}\left(\frac{x_{1}}{1-x_{1}}\right)+V^{\prime}\left(\frac{y}{1-y}\right)
$$

Setting $y=0.02$

$$
100\left(\frac{x}{1-x}\right)+89.1\left(\frac{0.01}{1-0.01}\right)=100\left(\frac{0.008478}{1-0.008478}\right)+89.1\left(\frac{0.02}{1-0.02}\right)
$$

Which solution leads to $\mathrm{x}=0.0124$. Setting $\mathrm{y}=$ 0.03 we obtain

$$
100\left(\frac{x}{1-x}\right)+89.1\left(\frac{0.01}{1-0.01}\right)=100\left(\frac{0.008478}{1-0.008478}\right)+89.1\left(\frac{0.03}{1-0.03}\right)
$$

Which solution leads to $x=0.0264$. The previous points found are plotted in the operating line. The approximate slope at $x_{1}, y_{1}$ can be calculated by

$$
\text { slope } \cong-\frac{k_{x}^{\prime} a\left(1-y_{1}\right)}{k_{y}^{\prime} a\left(1-x_{1}\right)}=-\frac{0.169(1-0.01)}{0.0739(1-0.008478)}=-2.28336(6)
$$

If we plot this line, the values at $M_{1}$ are $y_{i 1}=$ 0.00707, $x_{i 1}=0.009758$. Data for equilibrium line is presented in Fig. 2 according to information provided in Table 1 [11].
Table 1. Equilibrium data for the system under study.

\begin{tabular}{ccc}
\hline \multicolumn{3}{c}{ equilibrium data } \\
\hline $\begin{array}{c}\boldsymbol{x} \text { (mol } \\
\text { fraction) }\end{array}$ & $\begin{array}{c}\text { partial } \\
\text { pressure(mm Hg) }\end{array}$ & $\begin{array}{c}\boldsymbol{Y} \text { (mol } \\
\text { fraction) }\end{array}$ \\
\hline 0 & 0 & 0.000 \\
\hline 0.021 & 12.000 & 0.016 \\
\hline 0.026 & 15.000 & 0.020 \\
\hline 0.031 & 18.200 & 0.024 \\
\hline 0.041 & 24.900 & 0.033 \\
\hline 0.050 & 31.700 & 0.042 \\
\hline 0.074 & 50.000 & 0.066 \\
\hline 0.096 & 69.600 & 0.092 \\
\hline 0.137 & 114.000 & 0.150 \\
\hline 0.175 & 166.000 & 0.218 \\
\hline 0.210 & 227.000 & 0.299 \\
\hline 0.241 & 298.000 & 0.392 \\
\hline 0.297 & 470.000 & 0.618 \\
\hline & & \\
\hline
\end{tabular}

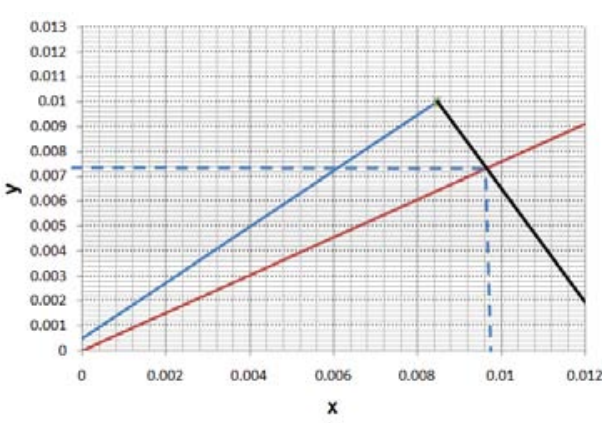

Fig. 2. Operation line (blue), equilibrium line (red) and interface composition $\left(P_{1} M_{1}\right)$ (dashed line).

Following, we proceed to determine $(1-y)_{i M}$ after equation (7)

$$
\begin{gathered}
(1-y)_{i M}=\frac{\left(1-y_{i 1}\right)-\left(1-y_{1}\right)}{\ln \left[\frac{\left(1-y_{i 1}\right)}{\left(\left(1-y_{1}\right)\right.}\right]} \\
(1-y)_{i M}=\frac{(1-0.00707)-(1-0.01)}{\ln \left[\frac{(1-0.00707)}{((1-0.01))}\right]}=0.9914 \\
(1-x)_{i M}=\frac{\left(1-x_{i 1}\right)-\left(1-x_{1}\right)}{\ln \left[\left(1-x_{i 1}\right) /\left(\left(1-x_{1}\right)\right)\right]}
\end{gathered}
$$

$(1-x)_{i M}=\frac{(1-0.009758)-(1-0.008478)}{\ln [(1-0.009758) /((1-0.008478))]}=0.9908(10)$

$$
\text { slope }=-\frac{k_{x}^{\prime} a(1-y)_{i M}}{k_{y}^{\prime} a(1-x)_{i M}}=-\frac{0.169(0.9914)}{0.0739(0.9908)}=-2.28822
$$

Replotting $P_{1} M_{1}, y_{i 1}=0.007072, x_{i 1}=0.009757$ for the slope at point 2

slope $=-\frac{k_{x}^{\prime} a\left(1-y_{2}\right)_{i M}}{k_{y}^{\prime} a\left(1-x_{2}\right)_{i M}}=-\frac{0.169(1-0.0005)}{0.0739(1-0)}=-2.28573$ 
The slope is essentially constant for $P_{1} M_{1}$ and $P_{2} M_{2}$ as a result, using an algorithm developed to find the intersection between the operation line and equilibrium line we found that $y_{i 2}=0.000125, x_{i 2}=0.00016$

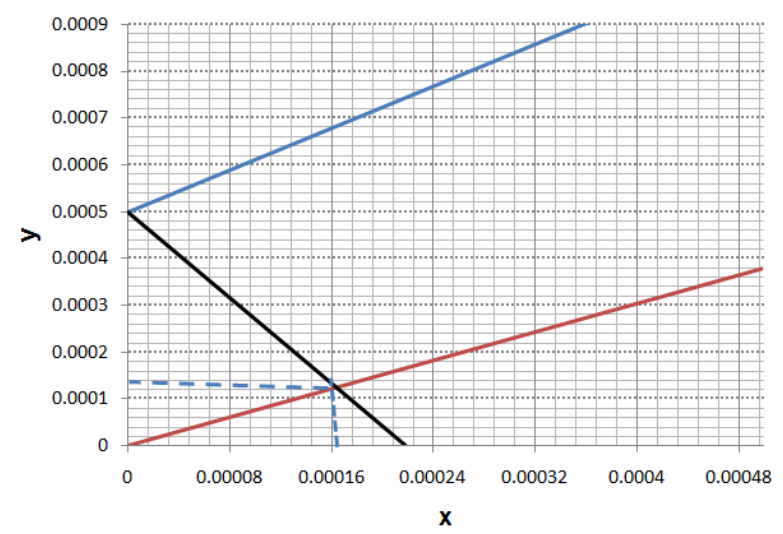

Fig. 3. Operation line (blue), equilibrium line (red) and interface composition $\left(P_{2} M_{2}\right)$ (dashed line).

For figure 2, we can also used equation (13)

$$
y_{2}=\operatorname{slope}\left(x_{2}-x_{1}\right)+y_{1}
$$

Considering the log mean driving force (14) [13]

$$
\left(y-y_{i}\right)_{M}=\frac{\left(y_{1}-y_{i 1}\right)-\left(y_{2}-y_{i 2}\right)}{\ln \left[\left(y_{1}-y_{i 1}\right) /\left(\left(y_{2}-y_{i 2}\right)\right)\right]}
$$

$$
\left(y-y_{i}\right)_{M}=\frac{(0.01-0.00707)-(0.0005-0.000125)}{\ln [(0.01-0.00707) /((0.0005-0.000125))]}
$$

$$
\left(y-y_{i}\right)_{M}=0.0013
$$

To calculate the total molar flow rate $\bar{V}=$ $\left(V_{1}+V_{2}\right) / 2=(90+89.14) / 2=89.57 \mathrm{~kg} \mathrm{~mol} / \mathrm{h}=$ $0.0248 \mathrm{~kg} \mathrm{~mol} / \mathrm{s}$.

Applying $(\bar{V} / S)\left(y_{1}-y_{2}\right)=k_{y}^{\prime} a z\left(y-y_{i}\right)_{M}$ leads to $(0.0248 / S)(0.01-0.0005)=0.0739 z(0.0013)$, $(0.0002363 / S)=0.000124 z$

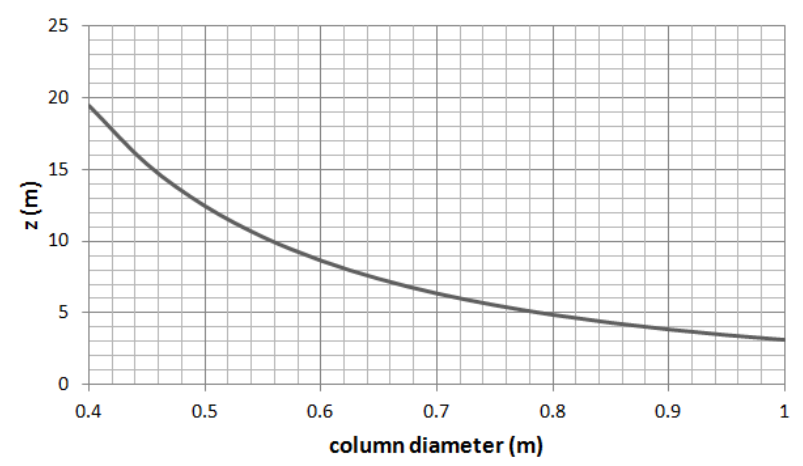

Fig. 4. Variation of height column (m) with column diameter (m).

After determination of the concentration changes in the column, the height of the column for a required outlet concentration of one of the components can be calculated [14]. For numerical purposes, we consider the case of tower diameter of $0.5 \mathrm{~m}$

$$
\begin{gathered}
\left([0.0002363 \cdot 4] /\left(\pi \cdot[0.5]^{2}\right)\right)=0.000124 z \\
0.0012=0.000124 z \\
z=9.74
\end{gathered}
$$

\section{Conclusions}

Absorption towers are used to retrieve different type of gases from the vapor phase into the liquid phase, but not necessarily only water. Packed towers are generally used for this purpose. It consists of a cylindrical column, or tower, with a gas inlet; entrance and a distributor at the top and outputs for gas and liquid. A tower is packed so it provides a large surface area to facilitate contact between liquid and gas. This allows continuous contact between the liquid and the gas in both the countercurrent flow and the parallel flow. The liquid is distributed and runs down through the packed bed, so that it exposes a large surface in contact with the gas. A study was performed to evaluate interface composition and height column in an absorption process. This is important particularly for the sequence of chemical and physical operations, operating conditions, construction specifications during process design to ensure proper mass transfer process and achieve the desired recovery, yield or mass transfer rate during the absorption process. Additionally, the model allow us to understand the variation of height column with column diameter

This work was supported by the Ministry of Education, Youth and Sports of the Czech Republic within the National Sustainability Programme project No. LO1303 (MSMT7778/2014), the European Regional Development Fund under the project CEBIA-Tech No. CZ.1.05/2.1.00/03.0089 and also by the internal project No. RVO/CEBIA/2019/003 "Vývoj recyklačních a zpracovatelských technologií".

\section{References}

1. S.M.Walas, Chemical Process equipment, Selection and design (Butterworth-Heinemann, 1990)

2. D. M. Himmelblau, Basic Principles and Calculations in Chemical Engineering. (Pearson Education, Pearson, 2002) 1

3. A. Pérez Sánchez, E. J. Pérez Sánchez, and R. Segura Silva, Nexo Rev. Científica, 29, 2, 83-104, ( 2016)

4. R. Darby and R. P. Chhabra, Chemical engineering fluid mechanics. (CRC Press, 2017)

5. H. Silla, Chemical process engineering: design and economics, (CRC Press, 2003)

6. J. T. Yeh, H. W. Pennline, and K. P. Resnik, Energy Fuels, 15,2, 274-278, (2001)

7. L. S. Tan, A. M. Shariff, K. K. Lau, and M. A. Bustam, J. Ind. Eng. Chem., 18, 6, 1874-1883, ( 2012)

8. E. Rahmandoost, B. Roozbehani, and M. H. Maddahi, Iranian Journal of Oil \& Gas Science and Technology 3,4,1-15, (2014) 
9. K. A. Hoff and H. F. Svendsen, Energy Procedia, 37, 952-960, (2013)

10. G. P. Towler and R. K. Sinnott, Chemical engineering design: principles, practice, and economics of plant and process design, ( Butterworth-Heinemann, 2013)

11. C. J. Geankoplis, Transport processes and unit operations, (Prentice Hall, 1993)

12. A. S. Foust, L. A. Wenzel, C. W. Clump, L. Maus, and L. B. Andersen, Principles of unit operations, (John Wiley \& Sons, Inc, New Delhi, 1980)
13. J. Welty, C. Wicks, and R. Wilson, Fundamentals of Momentum, heat, and Mass Transfer, (John Wiley and Sons, 2008)

14. H. D. Baehr, "Introduction. Technical Applications" in Heat and Mass Transfer, ( Springer, 2006) 